Proc. Indian Acad. Sci. (Earth Planet. Sci.), Vol. 94, No. 2, July 1985, pp. 91-97.

(C) Printed in India.

\title{
An analytical technique for rapid determination of surface rock density
}

\author{
G RAMADASS, S M VARAPRASADA RAO and $M$ S VIJAYA \\ RAGHAVA \\ Centre of Exploration Geophysics, Osmania University, Hyderabad 500007, India.
}

MS received 28 February 1984; revised 15 October 1984

\begin{abstract}
Computation of the coefficient of correlation between the Bouguer reduced gravity and the ground relief apparently helps minimize the subjectivity inherent in the Nettleton's method of surface rock density determination. The ideal density is the one that results in zero correlation between them. The iterative procedure in sweeping the calculations through the range of densities chosen can be avoided by taking advantage of the linear relationship between this coefficient and the density. Linear interpolation is therefore suggested to arrive at the ideal density. The suggested procedure consequently consists of correlation coefficient computations for the two-density extremum values within which the density of the surface rock formations is expected to lie. The computer program for this method is also presented. The procedure involved and the efficacy of the method are illustrated with some practical analyses.
\end{abstract}

Keywords. Surface rock density; correlation coefficient; Bouguer reduced gravity; ground relief; linear interpolation.

\section{Introduction}

Surface rock density determinations from field gravity measurements make use of the relation between the gravity variation and the ground relief. Operating on this relationship Nettleton (1939) first provided a basis for working out the correct surface rock density from graphical constructions. Seigert (1942) and Parasnis (1952) proposed analytical techniques to process gravity data free from any structural effects to obtain the surface density by the least squares procedure. Rao and Murthy (1973) examined the possibility for extending the Parasnis method in the presence of linear regional background. Nettleton's method however is more widely in use although the choice of the right density that renders the Bouguer anomaly least related to topographic changes remains purely subjective. Rao et al (1980) provided a statistical basis to minimize this difficulty by seeking an optimum value of the coefficient of correlation between the Bouguer reduced gravity and elevation. Here, the iterative procedure inherent in the approach is shown to be amenable to simplification by an interpolation process for more rapid evaluation of surface formation density.

\section{Basis of the method}

Nettleton's method of surface rock density determination is known to consist essentially of Bouguer reduction of the observed gravity values. Combined elevation correction is computed under this method for assumed values of density to obtain the reduced Bouguer anomaly along the entire traverse of measurements. The Bouguer anomaly is compared with the ground relief. The density, obtained from a range of 
values which gives least correlation with elevation, is taken as representative of the near surface formation density. Details of the basis behind the approach are presented by Rao et al (1980) who also proposed the computation of the coefficient of correlation to minimize the subjectivity of Nettleton's method.

Attempts by the authors to arrive at the minimum coefficient of correlation by repeat calculations for varied densities indicate that the correlation coefficient is linearly and inversely related to density as expected. In so far as densities higher than the correct value tend to produce a mirror image of the relief in the Bouguer anomaly, the correlation coefficient also seems to undergo reversal in its sign with densities larger than characteristic values of the near surface rock formations. The crossover point obviously indicates the ideal density with absolutely no relation to the ground relief to the corresponding Bouguer anomaly. However, errors of measurements in both the gravity and elevation obviate this possibility in practical situations. Consequently, the correlation coefficient obtains non-zero minimum values for practical data, the densities corresponding to which may be considered as the reliable range relevant to the field situation.

The choice of the minimum non-zero value of the correlation coefficient is difficult for the obvious reason that the number of iterations could be extremely large. Besides, the errors of gravity measurements prescribe the limit below which the value of correlation coefficient loses significance. It is therefore suggested that the density at the crossover point be corrected by the following factor assuming that the elevation measurements are of negligible error (Berëzkin 1967):

$$
\Delta \sigma= \pm \Delta g_{\text {error }} / 0.04185 \overline{\Delta h} \mathrm{~g} / \mathrm{cc}
$$

where, $\Delta g_{\text {error }}$ in milligals is the gravity measurements error and $\overline{\Delta h}$ is the average elevation in meters with respect to the chosen datum. The error in elevation measurements by repeat observations is of the order of $\pm 0.5 \mathrm{~m}$ in the present case.

The true density may thus be computed to an accuracy dependent on the accuracy of the gravity survey itself. Evidently, data on large average elevation over the datum are better suited for practical evaluations.

\section{Interpolation}

Since a linear relationship is expected between density and the corresponding value of the coefficient of correlation between the reduced gravity and the surface relief, by a suitable method of interpolation, the coordinates $(\sigma, 0)$ of the point $K$ shown in figure 1 may be found out from known values of any two points $A$ and $Q$ on the line $A K Q$. Thus, following James and Scarborough (1966), we get, $\gamma_{1}$ and $\gamma_{2}$ minimum and maximum

$$
\sigma=\sigma_{1}+\left(\sigma_{2}-\sigma_{1}\right)\left|\gamma_{1}\right| /\left(\left|\gamma_{1}\right|+\left|\gamma_{2}\right|\right)
$$

where $\sigma=$ density in $\mathrm{g} / \mathrm{cc}$ considered; $\gamma_{1}$ and $\gamma_{2}$ are corresponding coefficients of correlation. By substituting the numerical values of $\sigma_{1}, \gamma_{1}, \sigma_{2}$ and $\gamma_{2}$, the density corresponding to the ideal situation of zero correlation can be evaluated. The density correction is computed using (1) to prescribe the limits within which the actual density of surfacial formation lies. 


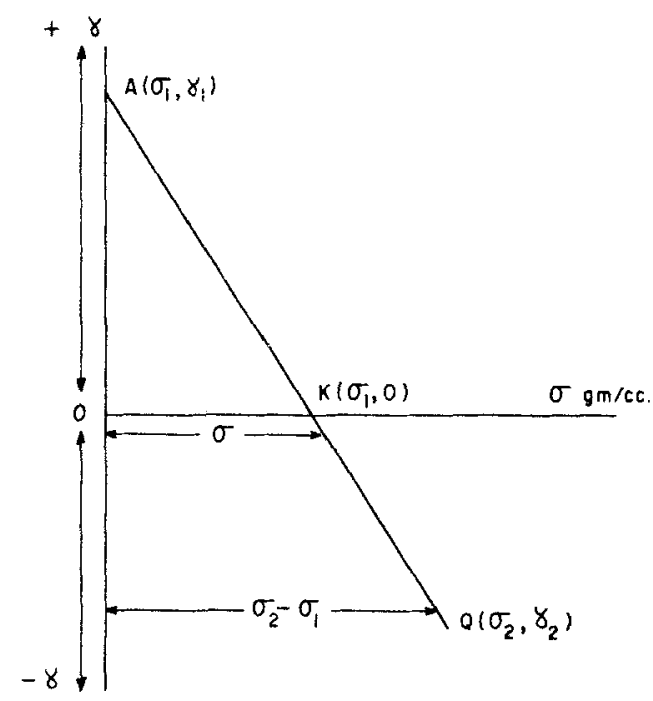

Figure 1. Fixing the coordinates of an intermediate point by interpolation.

\section{Calculation procedure}

Practical density evaluations by the present method require computation of the correlation coefficients corresponding to any two assumed density extremum values to the combined correction factor. The Fortran program developed for this method is listed in the appendix. It is only necessary to prescribe the minimum and maximum possible densities within which the actual density is expected to occur in practical cases. The tedious course of considering the correlation coefficients by incremental changes from the assumed density therefore becomes unnecessary.

\subsection{Test analysis-1}

Gravity and ground relief data of a couple of traverse runs over the Kamthi sandstones of the Lower Gondwana formations in a part of the Godavary valley, India, have been used to compute the density of these sandstones by the present approach. The basic data of these two traverses roughly $500 \mathrm{~m}$ apart are as shown in figures $2 \mathrm{a}, \mathrm{b}$. As may be noticed, the total elevation change in these two traverses is not considerable, but careful gravity measurements, provide an accuracy to enable the density determination to be reliable.

Coefficients of correlation computed following Cramer (1946) for varied densities with an increment of $0.01 \mathrm{~g} / \mathrm{cc}$ from the initial values of $2.0 \mathrm{~g} / \mathrm{cc}$ and plotted against the corresponding dẹnsities are shown in figures $3(\mathrm{a})$ and $3(\mathrm{~b})$ for the data of figures 2(a) and 2 (b) respectively. Linear relationship between these two parameters within experimental errors in evidenced in these figures. The densities corresponding to zero correlation between the reduced gravity and the elevation are seen to be $2.40 \mathrm{~g} / \mathrm{cc}$ and $2.43 \mathrm{~g} / \mathrm{cc}$ for the data of these traverses. Although the graphs in figure 3 are constructed 

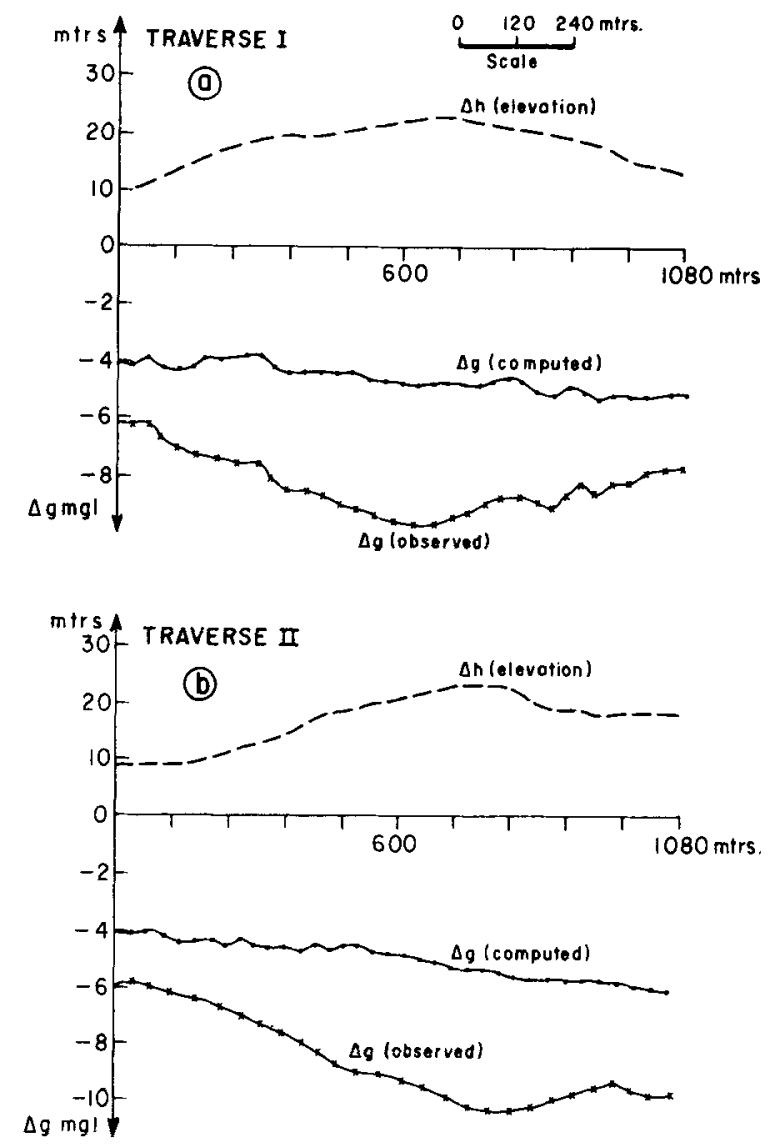

Figure 2. Gravity and elevation plots.

to illustrate the nature of the relationship between density and correlation coefficient, iterative and hence tedious calculations are not practically warranted. The ideal density corresponding to the zero correlation coefficient value may be directly computed by the interpolation technique using (2). The minimum and maximum density values prescribed for the two cases and the final densities computed by (1) and (2) are summarised in table 1 .

\subsection{Test analysis -2}

The present technique is used to estimate the surface density of sedimentary rocks consisting of phyllitic shales and limestones in parts of Varikunta-Zangamrajupalle belt in eastern Cuddapah basin. An average density of $2.65 \mathrm{~g} / \mathrm{cc}$ was obtained for these formations.

In order to examine the tenability of the final results, densities of 10 core samples of Kamthi (Lower Gondwana) formations and 50 core samples of phyllitic shales and 

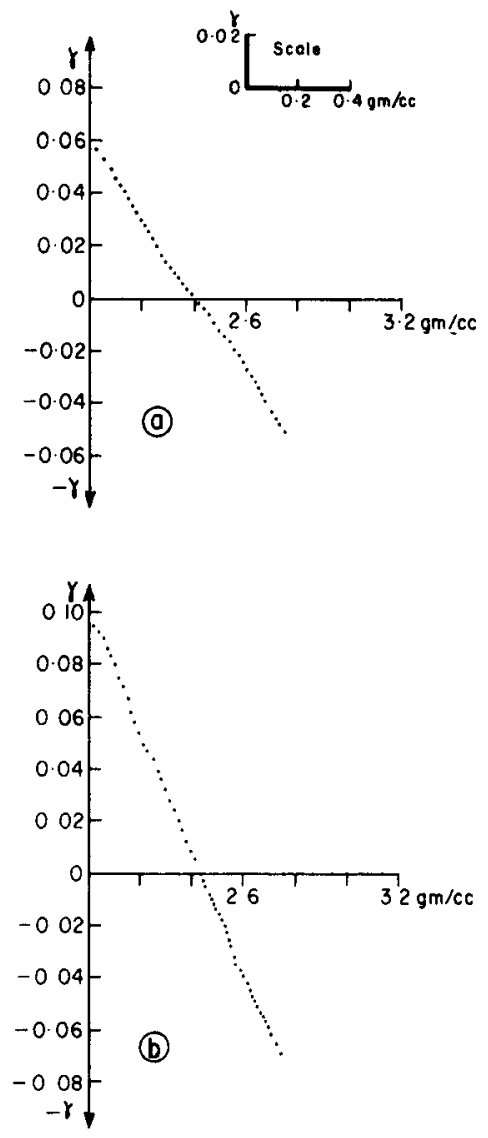

Figure 3. Relationship between correlation coefficient and density.

Table 1.

\begin{tabular}{|c|c|c|c|c|c|}
\hline $\begin{array}{l}\text { Traverse } \\
\text { no. }\end{array}$ & $\begin{array}{c}\text { Density } \\
\text { minimum } \\
\sigma_{1}(\mathrm{~g} / \propto)\end{array}$ & $\begin{array}{c}\text { Correlation } \\
\text { coefficient } \\
\gamma_{1}\end{array}$ & $\begin{array}{c}\text { Density } \\
\text { maximum } \\
\sigma_{2}(\mathrm{~g} / \propto \mathbf{c})\end{array}$ & $\begin{array}{c}\text { Correlation } \\
\text { coefficient } \\
\gamma_{2}\end{array}$ & $\begin{array}{l}\text { Density at } \\
\text { the cross over } \\
\text { point with } \\
\text { correction } \\
\text { factor } \\
\sigma(\mathrm{g} / \mathrm{cc})\end{array}$ \\
\hline I & $2 \cdot 0$ & 0.062 & $2 \cdot 74$ & -0.052 & $2 \cdot 40 \pm 0.08$ \\
\hline II & 2.0 & $.0 \cdot 099$ & $2 \cdot 74$ & -0.070 & $2.43 \pm 0.11$ \\
\hline
\end{tabular}

limestones (Cuddappah super group) from the bore holes in the vicinity of these traverses have been measured in the laboratory. Measurements on the dry samples collected yield values of $2.33 \pm 0.01 \mathrm{~g} / \mathrm{cc}$ and $2.63 \mathrm{~g} / \mathrm{cc}$ for the Kamthi and phyllitic shales and limestone formations respectively. 
Table 2.

\begin{tabular}{|c|c|c|c|}
\hline \multirow[b]{2}{*}{ Method } & \multicolumn{2}{|c|}{$\begin{array}{l}\text { Kamthi formations } \\
\text { (Lower Gondwana) }\end{array}$} & \multirow[t]{2}{*}{$\begin{array}{l}\text { Phyllitic shales and limestones } \\
\text { (Cuddappah super group) }\end{array}$} \\
\hline & $\begin{array}{c}\text { Traverse-I } \\
\text { Density } \\
\mathbf{g} / \mathfrak{c}\end{array}$ & $\begin{array}{c}\text { Traverse-II } \\
\text { Density } \\
\text { g/cc }\end{array}$ & \\
\hline Nettleton's & $2 \cdot 35$ & $2 \cdot 36$ & 2.59 \\
\hline Seigert's & $3 \cdot 24$ & $3 \cdot 30$ & 2.52 \\
\hline Parasnis's & 3.62 & 4.54 & 2.54 \\
\hline Present work & $2 \cdot 32$ & $2 \cdot 32$ & 2.65 \\
\hline
\end{tabular}

All the known methods were utilised on these field data and the results obtained by earlier methods as well as here are compared in table 2.

\section{Conclusion}

With the data of measured gravity and elevation and by prescribing the lowest and highest density values, surface rock density is reliably computed by the present technique. Use of any modern calculator or the given computer program (appendix) is recommended. Practical limits to the computed ideal density are prescribed by the accuracy of gravity measurements. Also it is evident that gravity data of traverses with large elevation changes are to be preferred.

\section{Acknowledgements}

The authors are grateful to Dr N L Mohan for guidance.

\section{Appendix}

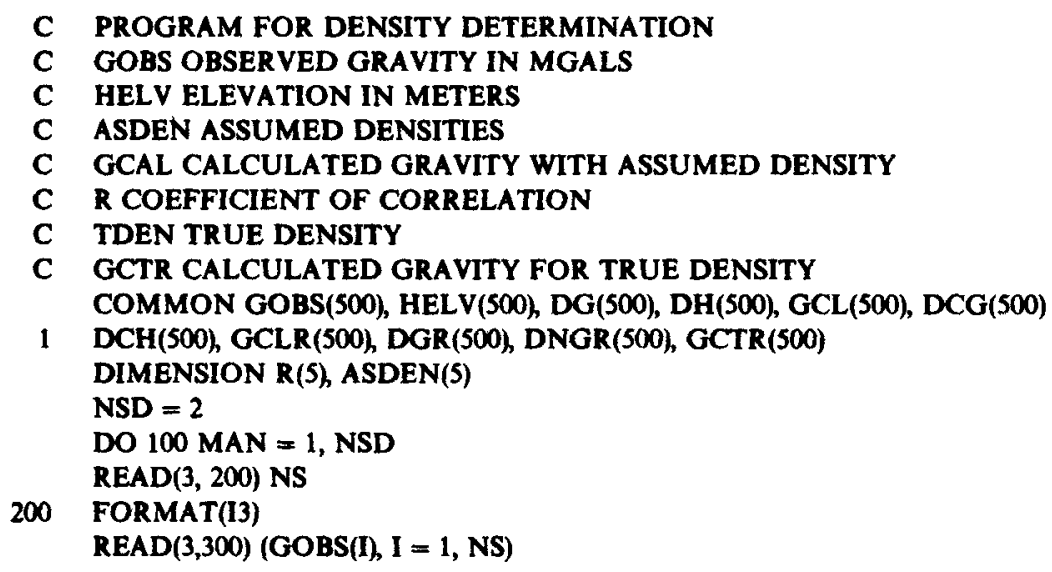


$\operatorname{READ}(3,400)(\operatorname{HELV}(I), I=1, \mathrm{NS})$

300

FORMAT(12F6.2)

400 FORMAT(16F5.2)

SGHS $=0.0$

SHSS $=0-0$

$\mathbf{M}=\mathbf{N S}-1$

DO $600 \mathrm{~L}=1,2$

$A=\mathbf{L}$

$\operatorname{ASDEN}(\mathrm{L})=1 \cdot 5^{*} \mathrm{~A}$

DO $700 \mathrm{~N}=1$, NS

$\operatorname{GCAL}(\mathrm{N})=$ GOBS$(\mathrm{N})+(0.3086-0.04185 * \operatorname{ASDEN}(\mathrm{L}))^{*} \operatorname{HELV}(\mathrm{N})$

700

CONTINUE

SUMG $=0.0$

SUMH $=\mathbf{0 . 0}$

SUMGS $=0.0$

SUMHS $=0.0$

SUMGH $=0 \cdot 0$

DO $800 \mathrm{~J}=1, \mathrm{M}$

$\operatorname{DCG}(J)=\operatorname{GCAL}(\mathrm{J}+1)-\operatorname{GCAL}(\mathrm{J})$

$\operatorname{DCH}(J)=\operatorname{HELV}(J+1)-H E L V(J)$

SUMG $=$ SUMG + DCH $(J)$

SUMH = SUMH + DCH(J)

SUMGS $=$ SUMGS + DCG $(\mathrm{J}) * D C G(J)$

SUMHS $=$ SUMHS + DCH $(\mathrm{J}) *$ DCH $(\mathrm{J})$

SUMGH $=$ SUMGH + DCG $(J) * D C H(J)$

800

CONTINUE

$\mathbf{A M}=\mathbf{M}$

S1 $=$ SUMHS $/ A M-($ SUMH/AM**2)

S2 $=$ SUMGS $/ A M-\left(\right.$ SUMH $/\left(\right.$ AM $^{*}$ AM) $\left.)\right)$

$\mathbf{S 1}=\mathbf{A B S}(\mathbf{S} 1)$

$\mathbf{S} 2=\mathbf{A B S}(\mathbf{S} 2)$

$\mathrm{SGH}=\mathrm{SQRT}(\mathrm{S} 1)$

SGG $=$ SQRT(S2)

CNSTP $=($ SUMGH/AM $)-($ SUMG*SUMH/(AM*AM $))$

600 CONTINUE

$R(L)=$ CNSTP $/($ SGG $*$ SGH $)$

$\mathbf{R N}=(\operatorname{ASDEN}(2)-\operatorname{ASDEN}(1))^{*} \mathrm{ABS}(\mathbf{R}(1))$

$\mathrm{DR}=\mathrm{ABS}(\mathrm{R}(1))+\mathrm{ABS}(\mathrm{R}(2))$

TDEN $=$ ASDEN $(1)+($ RN/DR $)$

WRITE $(4,900)$ TDEN

900 FOR MAT(E20-8)

100 CONTINUE

STOP

END

\section{References}

Berezkin V M Consideration of ground relief and the surfacial layer in gravity detailed surveys (Moscow: Nedra)

Cramer H 1946 Mathematical methods of statistics (Princeton: University Press)

James B and Scarborough 1966 Numerical mathematical analysis (New Delhi: Oxford \& IBH Pub. Co.)

Nettleton L L 1939 Geophysics 4176

Parasnis D S 1952 Mon. Not. R. Astron. Soc. 6252

Seigert A J F 1942 Geophysics 729

Rao S M V, Bhimasankaram V L S and Soloview G A 1980 J. Assoc. Explor. Geophys. 143

Rao V B and Murty B V S 1973 Pure Appl. Geophys. 1101927 